\title{
Em direção à construção automática de Mapas Conceituais a partir de textos
}

Title: Towards the automatic construction of Concept Maps from texts

Juliana Hiroko Kowata

Vitória - ES - Brasil

juliana.kowata@gmail.com

\author{
Davidson Cury \\ Universidade Federal do Espírito \\ Santo - UFES \\ Vitória - ES - Brasil \\ dedecury@gmail.com
}

\author{
Maria Claudia Silva Boeres \\ Universidade Federal do Espírito \\ Santo - UFES \\ Vitória - ES - Brasil \\ boeres@inf.ufes.br
}

Resumo A partir do pressuposto de que a construção, avaliação e evolução dos mapas conceituais são mecanismos que instigam o aprendiz a se tornar sujeito ativo do processo de aprendizagem, corroborando a ação colaborativa entre professores e aprendizes, o presente artigo propõe uma abordagem computacional para a construção de mapas conceituais a partir de documentos em Língua Portuguesa do Brasil com vistas a superar as dificuldades da construção de mapas conceituais a partir do "zero" e a possibilitar a ressignificação de conteúdos textuais.

Palavras-Chave: Mapas Conceituais, Processamento de Linguagem Natural, Informática na Educação.

\begin{abstract}
From the assumption that the construction, evaluation and evolution of the concept maps are mechanisms that push the learner to become an active subject of the learning process, supporting collaborative action between teachers and learners, this paper proposes a computational approach for the construction of concept maps from documents in Portuguese of Brazil in order to overcome the difficulties of building concept maps from the "scratch" and to enable a way of giving new meanings to textual contents.
\end{abstract}

Keywords: Concept Maps, Natural Language Processing, Informatics in Education. 


\section{Introdução}

Nas sociedades da informação, a ubiquidade e a importância das novas tecnologias dão ensejo ao desenvolvimento de habilidades e competências específicas, as quais deveriam estar presentes nos currículos escolares. A educação nesse cenário exige uma abordagem em que o componente tecnológico não pode ser ignorado, visto que suas inovações e o seu impacto revestem-se de uma dimensão não puramente tecnológica, mas essencialmente econômica e social $[1,2,3]$. Cabe à tecnologia o papel de apoio, principalmente, no espaço da construção do conhecimento, criando condições para que o aprendiz, sujeito ativo da aprendizagem, aprenda ao fazer, levantar e testar ideias, experimentar, aplicar conhecimentos e representar o pensamento. Logo, a integração de diferentes tecnologias no currículo escolar - prática que fomenta o surgimento de novas maneiras de ensinar e aprender fundamenta-se tanto na introdução de novas tecnologias quanto na ressignificação das chamadas tecnologias convencionais, cabendo ao professor decidir quais veículos e linguagens privilegiar, levando os estudantes à melhor compreensão dos conteúdos trabalhados [4].

Nesta pesquisa, enfatizamos o uso dos recursos tecnológicos no apoio às práticas educacionais voltadas para a aprendizagem significativa e, de forma mais específica, delimitamos o problema ao uso de recursos tecnológicos com o intuito de promover a ressignificação de conteúdos estáticos, essencialmente expressos na forma de textos, em mapas conceituais. Assim, o escopo da pesquisa resume-se à definição de uma abordagem computacional para a construção de mapas conceituais a partir de textos em Língua Portuguesa do Brasil.

Formalmente, o problema consiste em tomar um documento $d$, com conteúdo expresso em português do Brasil, e representá-lo por meio de um mapa conceitual $m c$. O conteúdo do documento $d$ é constituído por um conjunto de sentenças $s_{1} \ldots s_{n}$, ou seja, $d=\left\{s_{1}, s_{2}, \ldots, s_{n}\right\}$. Para cada sentença $s_{i}$ definida por meio de linguagem natural, em que $i, i=1, \ldots, n$, designa o índice da sentença no documento $d$, é necessário identificar proposições $p_{i} \ldots p_{n}$ a serem extraídas de cada sentença, com o intuito de possibilitar a construção de um mapa conceitual $m c$. Uma proposição $p_{i}$ é definida por uma tripla de elementos ordenados $\left\{c 1_{i}-r_{i}-c 2_{i}\right\}$, nos quais $c 1_{i}$ e $c 2_{i}$ são conceitos e $r_{i}$ uma relação entre esses conceitos.

A transformação de uma sentença $s_{i}$ em triplas proposicionais no formato \{conceito - relação - conceito\} ou $\left\{c 1_{i}-r_{i}-c 2_{i}\right\}$ requer a identificação prévia dos elementos candidatos a conceitos e relações. Sob o ponto de vista computacional, enfrentamos a questão da descoberta de elementos candidatos a conceitos e relações de mapas conceituais a partir de uma sentença $s_{i}$, como um proble- ma de reconhecimento de padrões linguísticos e de entidades. A construção de proposições a partir de conceitos e relações é abordada como um problema de otimização que pode ser tratado por meio da seleção de um arranjo adequado entre elementos com o objetivo da obtenção de uma tripla.

Este trabalho está estruturado nas seguintes seções:

- A Seção 2 apresenta uma introdução à área de conhecimento sobre Mapas Conceituais, compilando definições e fundamentação teórica essenciais à compreensão do objeto da pesquisa;

- A Seção 3 apresenta uma revisão bibliográfica das abordagens computacionais para a construção de mapas conceituais, com a análise das abordagens similares à pesquisa, organizadas em um conjunto de características que propiciam a compreensão estruturada do estado da arte;

- A Seção 4, cerne da pesquisa, descreve a proposta de solução para a construção de mapas conceituais a partir de textos em Língua Portuguesa do Brasil, por meio do uso de recursos computacionais;

- A Seção 5 detalha o conjunto de atividades propostas para endereçar o problema da construção de mapas conceituais a partir de textos;

- A Seção 6 condensa a análise dos resultados obtidos com o estudo de caso; e

- A Seção 7 consolida nossas considerações finais e direcionamentos para futuros trabalhos.

\section{Organização de Conhecimento por meio de Mapas Conceituais}

Para fins desta pesquisa, adotamos a acepção de mapas conceituais como modelo de domínio, representado pelo artefato concreto, na forma de diagrama, que observa um modelo de especificação válido, derivado de uma linguagem de especificação. Expresso por um artefato concreto, o mapa conceitual é uma ferramenta que auxilia no processo de ensino e aprendizagem, permitindo a conciliação de diversas conceitualizações sobre um mesmo assunto.

Os Mapas Conceituais são singulares em relação a outras representações de conhecimento devido à fundamentação teórica, à topologia semi-hierárquica, à existência de relações rotuladas e à forma de definição dos vértices [5].

Os Mapas Conceituais são fundamentados pela Teoria da Aprendizagem Significativa, que considera que a estrutura cognitiva de cada indivíduo consiste em um espaço organizado e hierarquizado. No processo de aprendizagem, o indivíduo estabelece conexões proposicionais 
entre os novos conceitos e ideias e o conhecimento existente por meio de mecanismos de "ancoragem" [5]. Das premissas teóricas derivam-se as características estruturais e a dinâmica para construção dos Mapas, Conceituais:

a) conceitos são organizados de forma semihierárquica em que os conceitos específicos "ancoram-se" aos conceitos gerais;

b) conceitos são rotulados por meio de um número reduzido de palavras que definem "uma regularidade percebida em objetos e eventos";

c) a relação entre dois conceitos deve ser rotulada de modo que proposições sejam elaboradas.

Cabe a observação de que a organização hierárquica em um Mapa Conceitual está longe de ser uma prática pacificada. Ruiz-Primo e Shavelson [16] questionam a necessidade de existência de estruturas hierárquicas, afirmando que a organização depende mais do conteúdo do conhecimento que está sendo organizado, e menos de questões metodológicas e conceituais. Safayeni et al [17] defendem o uso de Mapas Conceituais para a representação de relacionamentos estáticos e propõem os Mapas Conceituais Cíclicos, uma extensão de Mapas Conceituais, nos quais a existência de ligações não hierárquicas permitiria a representação de relacionamentos funcionais ou dinâmicos entre conceitos, tais como causalidade, probabilidade, correlação. Em mapas conceituais hierárquicos, os conceitos tendem a se agrupar abaixo de alguns conceitos centrais, configurando um domínio específico. Os conceitos que compartilham um mesmo conceito ancestral pertencem ao mesmo domínio.

Também é necessário destacar que a organização do conhecimento por meio do mapa conceitual não visa o compartilhamento da aprendizagem, pois a aprendizagem, como processo interno e de responsabilidade individual, não está em condição de ser compartilhada. O mapa conceitual atua no compartilhamento de significados dos conceitos, que precisam ser discutidos, negociados e sujeitos a consenso [6].

Particularmente, interessamo-nos primeiramente pela aplicação de mapas conceituais como recursos de apoio ao processo de ensino e aprendizagem, dentro de um contexto educacional cujas práticas estejam alicerçadas na aprendizagem significativa, pois, consideramos que a ressignificação de conteúdos por meio de mapas concei- tuais favorecem a comunicação com leitores humanos. Secundariamente, estudamos o mapa conceitual enquanto representação intermediária para construção de ontologias.

\section{Revisão e Classificação do Estado da Arte}

Segundo [7], nesta década, houve um crescente interesse da comunidade acadêmica pela aplicação de recursos computacionais para a aquisição de conhecimento de textos e de outras fontes de dados e na sua representação em forma de mapas conceituais.

As pesquisas desta área encontram nos mapas conceituais um caminho para ressignificação do conteúdo disponível na web, em bibliotecas digitais, enciclopédias, jornais online e outros repositórios de dados.

Nesta área de pesquisa, os principais desafios residem na busca pela independência do auxílio humano no processo de construção de mapas conceituais, como forma de superar as dificuldades de construção a partir do "zero" e na redução de tempo e esforços para a aquisição de conhecimento sobretudo, em domínios de conhecimento extensos e dependentes de especialistas

Ao longo desta seção, definimos um conjunto de características de análise para as diferentes abordagens sobre a temática, com o intuito de propiciar um entendimento estruturado o estado da arte. As características definidas, organizadas em forma de perspectivas e classes de análise, estão ilustradas pela Figura 1. Esse conjunto de perspectivas sustenta a revisão das publicações acadêmicas relacionadas com a construção automática e semiautomática de mapas conceituais.

São três as principais perspectivas de análise:

i. Objetivos da Pesquisa;

ii. Fonte de Dados; e

iii. Estrutura do Mapa Conceitual resultante.

A seguir, explicamos com mais detalhes, como organizamos as perspectivas de análise de abordagens similares, por meio de classes. 


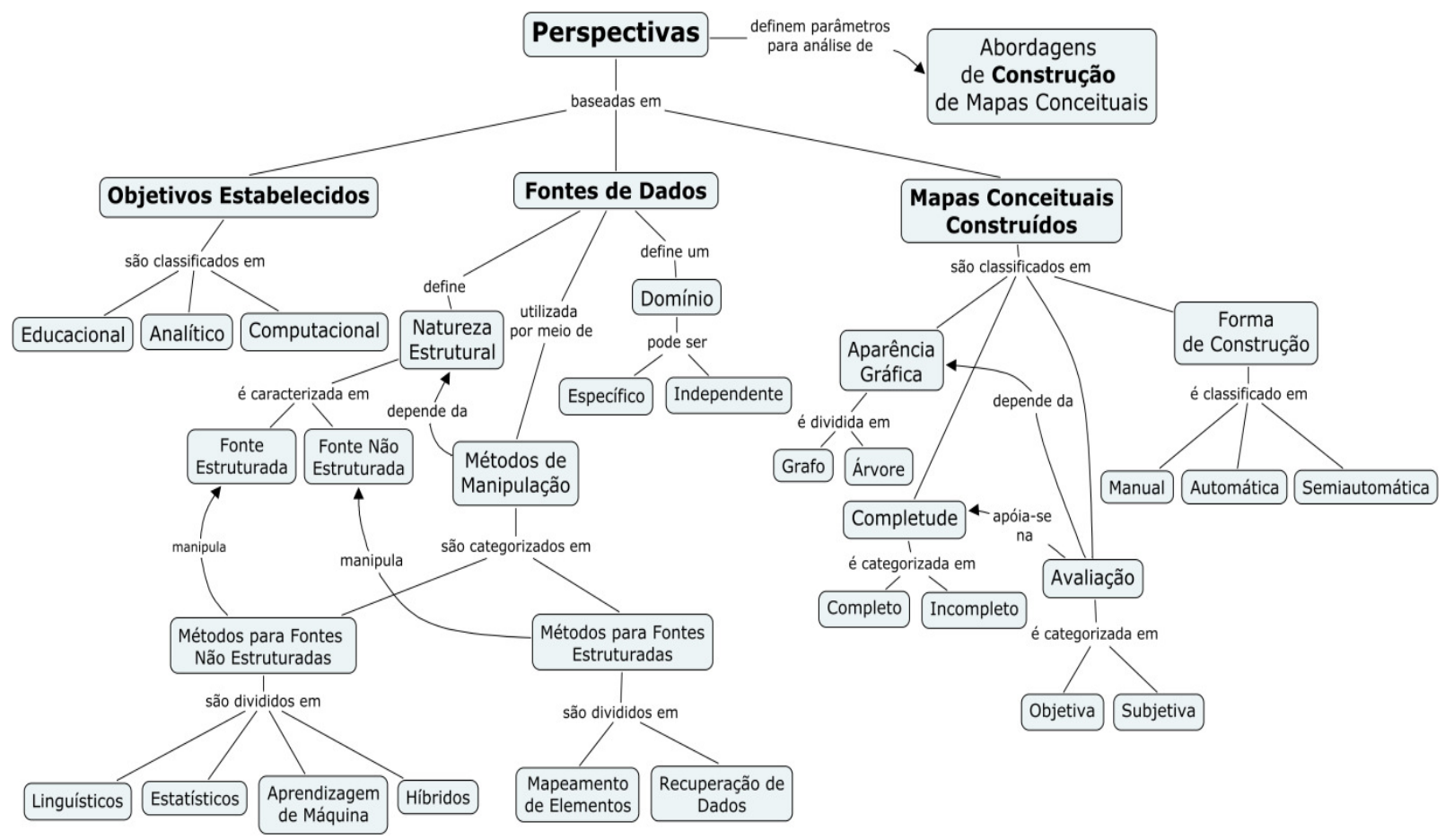

Figura 1. Perspectivas e Classes para Análise de Abordagens de Construção de Mapas Conceituais

\subsection{Perspectiva baseada nos Objetivos da Pesquisa}

Os objetivos definidos pela pesquisa para a construção de mapas conceituais direcionam a escolha da fonte de dados e definem uma variedade de requisitos, tais como: o público-alvo, o nível de legibilidade, a riqueza das proposições, entre outros.

Propomos as seguintes classes de acordos com a perspectiva baseada nos objetivos da pesquisa: classe educacional, classe analítica e classe computacional.

Na classe educacional, o principal objetivo é o uso de mapas conceituais como recursos complementares no processo de aprendizagem. Entre as abordagens que se enquadram nesta classe, mencionamos aquelas que:

- Promovem a construção interativa de mapas conceituais [18][19];

- Permitem que professores acompanhem a compreensão de alunos em tópicos específicos apresentados em ambientes de aprendizagem tradicionais [20] ou em ambientes virtuais de aprendizagem [21]; e

- Resumem e compartilham conteúdo digital [22, 23].

A classe analítica é caracterizada pelo uso de mapas conceituais como ferramentas para especialistas de domínio envolvidos em atividades de exploração, análise e reconhecimento de padrões em fontes de dados considerados extensas. Esse é o contexto das abordagens que:

- Exploram registros históricos de alunos, buscando por padrões de aprendizagem [24, 25, 26, 27, 28];

- Exibem informações para os especialistas de domínio [29, 30, 31, 32]; e

- Propõem o uso de mapas conceituais como ferramentas para acesso, busca e análise de dados em bibliotecas digitais [33].

Na classe computacional, o fio condutor consiste na manipulação de mapas conceituais para a aquisição de conhecimento por meio de aplicações de software. Nesta classe estão as pesquisas que utilizam os mapas conceituais como representações intermediárias entre o texto e as ontologias de domínio [34, 35].

\subsection{Perspectiva baseada nas Fontes de Dados}

A fonte de dados usada por uma abordagem impacta todo o processo de construção de mapas conceituais. Como uma entrada, a natureza estrutural da fonte de dados atua tanto como parâmetro de escolha do método de sua manipulação, quanto como uma restrição que determina o nível de dependência do domínio. Abaixo da perspectiva da fonte de dados, determinamos pontos de vista mais específicos, e definimos: (i) natureza estrutural; (ii) método de manipulação, e (iii) dependência de domínio. 


\subsubsection{Perspectiva da Natureza Estrutural}

A natureza estrutural da fonte de dados é definida pela organização dos dados. A partir deste ponto de vista, as fontes de dados usadas nas abordagens são organizadas em duas classes: na classe das fontes de dados estruturadas e na classe das fontes de dados não estruturadas. $\mathrm{Na}$ classe das fontes de dados não estruturadas, textos em linguagem natural são as fontes primitivas para extração dos elementos de mapas conceituais. Entre as abordagens que usam dados não estruturados, podemos mencionar aqueles que trabalham com:

- Textos produzidos por especialistas de domínio [18, 33, 34, 35];

- Textos produzidos por estudantes em resposta a questionários [25] ou a partir de um tema proposto [19];

- Textos científicos como, por exemplo, artigos acadêmicos [25], resumos de teses e dissertações [23];

- Mensagens de fóruns de discussão [21];

- Textos jornalísticos e didáticos [31, 32].

A classe das fontes de dados estruturadas apresenta dados organizados com algum nível de formalismo. Implementações para modelos conceituais e de ontologias de domínio são exemplos de fontes de dados estruturadas e estão presentes nas abordagens que utilizam respostas tabuladas de estudantes [24, 27, 28, ] e nas que utilizam ontologias de domínio [20,30].

\subsubsection{Perspectiva do Método de Manipulação}

$\mathrm{O}$ vínculo entre os métodos e técnicas computacionais aplicados na construção automática e semiautomática de mapas conceituais e a natureza estrutural da fonte de dados determinam a distinção dos métodos para fontes de dados não estruturadas dos métodos para fontes de dados estruturadas.

Os métodos que utilizam fontes de dados não estruturadas guardam um estreito relacionamento com o campo do Processamento de Linguagem Natural e todos eles poderiam, sob este critério, ser igualmente denominados de métodos baseados em métodos linguísticos. Entretanto, a presença de técnicas de manipulação linguística não é condição suficiente na definição da natureza técnica da abordagem [36]. Por isso, a caracterização considera a principal técnica utilizada na descoberta de conhecimento de textos. As classes para os métodos de manipulação são qualificadas em classe de Métodos Línguísticos, classe de Métodos Estatísticos, classe de Métodos de Aprendizagem de Máquina e, na impossibilidade de uma classificação única, há a classe dos Métodos Híbridos [34, 35].

A classe dos Métodos Linguísticos é caracterizada pelo uso de técnicas de linguística computacional [36] que utilizam recursos de análise morfológica, sintática, semântica, pragmática e do discurso. Tais técnicas são extremamente relacionadas com as características estruturais dos textos e baseiam-se, principalmente, na identificação de padrões linguísticos, na detecção de termos por meio de gramáticas que definem regras sintáticas, na definição de papéis temáticos e no reconhecimento de entidades nomeadas. De forma geral, os métodos linguísticos são mais precisos do que os Métodos Estatísticos, mas normalmente requerem o auxílio de bases de conhecimentos externos, tais como dicionários, thesaurus e banco de dados lexicais [35]. Neste grupo estão abordagens de Pérez e Vieira [31, 32], Richardson e Fox [22] e Richardson e outros [23].

Na classe dos Métodos Estatísticos, pode-se observar a utilização de técnicas baseadas em indicadores quantitativos [36]. De forma geral, tais técnicas produzem informações que permitem a análise da frequência de um termo e coocorrências entre termos em documentos ou corpus. As técnicas mais populares são a análise de frequência de repetição de termos ou padrões de palavras, o cálculo de pesos que indicam a relevância de termos em um conjunto de documentos (TF-IDF) e técnicas de agrupamento de documentos (clusterização). A grande contribuição dos métodos estatísticos está na relativa simplicidade de manipulação do documento, independente de conhecimento sobre as estruturas linguísticas das sentenças. O aspecto negativo a ser destacado é a imprevisibilidade dos resultados e a inadequação na representação semântica das sentenças [35]. Neste grupo estão abordagens de Gaines e Shaw [29] e de Clariana e Koul [37].

Na classe dos Métodos de Aprendizagem de Máquina utilizam-se técnicas de aprendizagem de máquina para a extração de elementos do texto. São técnicas que aplicam vários algoritmos para apoiar a descoberta de conceitos e suas relações [36] e são normalmente utilizados em conjunto com métodos estatísticos. Exemplos de métodos de aprendizagem de máquina podem ser encontrados nos algoritmos utilizados na descoberta de elementos coocorrentes e que podem caracterizar regras de associação, na identificação de palavras-chaves e taxonomias entre elementos [35].

A classe dos Métodos Híbridos caracteriza-se pela combinação de técnicas linguísticas, técnicas de aprendizagem de máquina e técnicas estatísticas de forma que não se pode precisar a técnica dominante. As abordagens híbridas estão presentes em Alves et al. [18], Lau et al. [21], Valerio e Leake [33] e Zouaq e Nkambou [34, 35].

Os métodos que utilizam fontes de dados estruturadas geralmente aplicam métodos de Mapeamento de Elementos ou Métodos de Recuperação de Dados. Esses métodos, na maioria das vezes, utilizam técnicas de mapeamento de elementos e técnicas de recuperação de dados. 
Baseado nestas técnicas, identificamos duas grandes classes para manipulação de fontes de dados estruturadas: a classe dos Métodos de Mapeamento de Elementos e dos Métodos de Recuperação de Dados.

As abordagens de Graudina e Grundspenkis [20] e Kumazawa e outros [30] podem ser enquadradas na classe dos métodos de Elementos de Mapeamento porque elas tratam do mapeamento de conceitos, propriedades e associações existentes em ontologias de domínio para elementos de mapas conceituais. As abordagens de Bai e Chen [24], Chen e outros [26], Lee e outros [27], Tseng e outros [28] não requerem grande esforço na identificação de conceitos de um mapa conceitual porque os definem no momento em que estabelecem uma questão focal. Portanto, estas abordagens podem ser enquadradas dentro da classe de Métodos de Recuperação de Dados para recuperação de conceitos armazenados na fonte de dados.

\subsubsection{Perspectiva da Dependência de Domínio}

Segundo o domínio, observamos que as abordagens podem ser distribuídas na classe independente de domínio ou na classe específica de domínio.

As abordagens da classe independente de domínio não apresentam restrição para a construção de mapas conceituais a um domínio específico e nem requerem conhecimento prévio sobre o mesmo. Nesta categoria se enquadram os trabalhos de Alves e outros [18], Pérez e Vieira [31, 32] e Valerio e Leake [33].

As abordagens da classe específica de domínio manipulam fontes de dados pertencentes a um domínio específico, tais como: E-learning [26] e Informática aplicada à Educação [34, 35], Fisiologia e Funcionamento do Coração Humano [19], Sistemas de Manufatura apoiados por Computador [29], Ciência da Computação [20, 22, 23], Ciência da Sustentabilidade [30]. Os trabalhos de Bai e Chen [24], Chang e outros [25], Lau e outros [21], Lee e outros [27] e Tseng e outros [28] não são, necessariamente, direcionados a um domínio específico, entretanto a independência de conhecimento prévio do domínio é comprometida quando a abordagem adota o planejamento prévio de questões focais e a identificação de conceitos associados.

\subsection{Perspectiva baseada nos Mapas Constru- ídos}

Considerando a perspectiva de saída da abordagem, o mapa conceitual construído pode ser analisado considerando (i) a aparência gráfica, (ii) a completude em relação à sua definição, (iii) a forma de construção e (iv) os mecanismos propostos para avaliação de sua qualidade.

A aparência gráfica de um mapa conceitual pode ser diretamente observada a partir do mapa conceitual. Caso exista uma topologia explícita, o mapa conceitual pertence à classe dos mapas em forma de árvore, senão, à classe da estrutura na forma de grafos. As definições de ambas as estruturas matemáticas podem ser encontradas na Teoria de Grafos [38].

Quanto à completude, um mapa conceitual pode ser analisado em relação à aderência aos elementos definidos na Teoria de Mapas Conceituais, caracterizando-se classes de mapas completos ou incompletos. Em mapas conceituais ditos incompletos, proposições não podem ser identificadas, pois não há rótulos para as relações ou sua semântica é insuficiente para o propósito de gerar proposições, ao contrário dos mapas completos nos quais as proposições são claramente definidas.

Quanto à forma de construção, as abordagens variam na proposta para a construção de representações gráficas. Algumas apresentam recursos automáticos e nativos, outras utilizam recursos para integração a ferramentas de terceiros ou simplesmente não entram no mérito da construção gráfica. Na construção de representação da classe automática, a abordagem apresenta um recurso nativo que constrói o mapa conceitual visualmente, sem a intervenção humana nesta construção. Dentre as abordagens que se enquadram nesta categoria estão a de Bai e Chen [24], Chang e outros [25], Chen [26], Kumazawa [30], Lau e outros [21], Lee e outros [27], Tseng e outros [28] e Zouaq e Nkambou [34, 35]. Nas abordagens da classe semiautomática, um conjunto de proposições são geradas e importadas por ferramentas de representação visual, como observado em Alves e outros [18], Clariana e Koul [19], Gaines e Shaw [29], Graudina e Grundspenkis [20], Richardson e Fox [22], Richardson e outros [23]. Já na classe de construção manual, as abordagens extraem apenas os conceitos e as relações, mas não definem proposições. Por isso, o mapa deve ser construído manualmente em uma ferramenta apropriada, como em Valerio e Leake [33].

Quanto à avaliação, que consiste na validação de proposições no mapa conceitual e de elementos estruturais do mapa conceitual construído, as classes são denominadas de classe Subjetiva e classe Objetiva. A avaliação na classe subjetiva é conduzida por meio de especialistas humanos que utilizam seus próprios critérios na validação do mapa conceitual, impossibilitando uma avaliação uniforme e independente do especialista. As abordagens analisadas utilizam quase que exclusivamente esta abordagem. A avaliação na classe objetiva pode ser conduzida tanto por especialistas humanos quanto por recursos computacionais, pois se baseiam em critérios de pontuação, originalmente definidos por Novak e Gowin, para proposições válidas, níveis de hierarquia, número de ramificações, existência de cross-links e exemplos específicos [6]. 


\section{Visão Geral da Abordagem}

A abordagem que propomos busca resguardar a fidelidade ao conteúdo do texto original, assegurando a compreensibilidade dos mapas conceituais construídos e, por isso, necessita enfrentar os desafios inerentes à manipulação da linguagem natural, além das particularidades da Língua Portuguesa. Por isso, a adoção de métodos e técnicas que restrinjam a perda semântica no mapeamento texto-mapa conceitual sem comprometer a essência do conteúdo e sem limitar a leitura humana, é crucial para o êxito da abordagem proposta.

Dentre as abordagens encontradas e relatadas em [7] encontramos números importantes: 10 das 15 abordagens, ou $66,67 \%$, usam fontes de dados não estruturadas; destas, metade constrói mapas conceituais ditos completos por meio de métodos híbridos e métodos linguísticos. As opções metodológicas para esta pesquisa não poderiam ser realizadas à margem dos dados expostos. Levando-se em consideração os resultados apresentados pelas pesquisas similares desenvolvemos uma predileção natural pelos métodos linguísticos e híbridos para tratar do problema da representação do conteúdo de um documento em Língua Portuguesa por meio de mapas conceituais.

Com vistas a clarificar o problema, lançamos mão da analogia entre o documento e o brinquedo de encaixe.

No brinquedo de encaixe, peças podem ser arranjadas de diversas maneiras, produzindo diferentes módulos.
Analogamente, no documento, as sentenças são módulos constituídos por peças, no caso, por peças linguísticas, tais como: palavras, números e sinais de pontuação. Estas peças linguísticas são organizadas observando-se a sintática, a semântica e a pragmática.

Tanto no conteúdo de um documento como em módulos construídos a partir das peças de encaixe, pode-se observar a existência de unidades atômicas de construção.

O rearranjo das peças do brinquedo permite novas construções, assim como a recombinação das peças linguísticas admite outras representações, sendo a representação proposicional a peremptória para a construção de mapas conceituais. A partir da definição da analogia, como exposta anteriormente, propomos uma abordagem em que o conteúdo de um documento deve ser fragmentado até que suas peças, de natureza linguística, tornemse disponíveis.

Posteriormente, as peças linguísticas são reconstruídas na forma de conceitos e relações em mapas conceituais. A expressão síntese da abordagem consiste na dicotomia "desconstruir-reconstruir". Equacionando o problema, projetamos um modelo de processo composto por um conjunto de atividades que se concatenam por meio de suas entradas e saídas, formando um túnel, de sentido único, linear, como ilustrado na Figura 2.

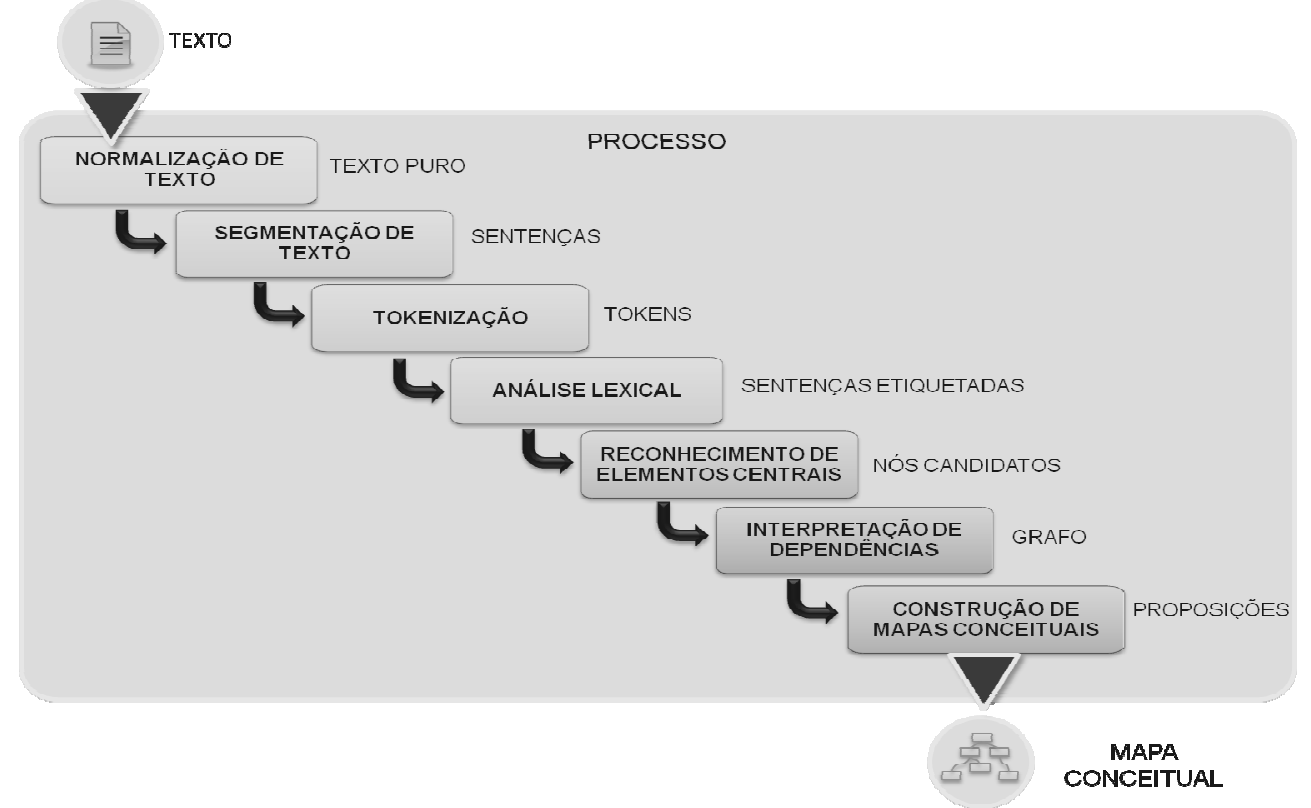

Figura 2. Modelo de Processo para Construção de Mapas Conceituais a partir de Textos 


\section{Atividades}

Nesta seção, cada uma das atividades será explicada em mais detalhes. O processo para a construção de mapas conceituais a partir de textos é constituído por sete atividades:

(i) Normalização de Texto;

(ii) Segmentação de Texto;

(iii) Tokenização;

(iv) Análise Lexical;

(v) Reconhecimento de Elementos Centrais;

(vi) Interpretação de Dependências e

(vii) Construção de Mapas Conceituais.

As atividades são coordenadas de forma sequencial, do primeiro ao último, orquestradas de forma que a cada atividade executada seja produzido um único artefato que será tomado como insumo para a atividade seguinte, partindo de um documento para a construção do mapa conceitual.

\subsection{Normalização de Texto}

A primeira atividade é a responsável por eliminar os marcadores de formatação existentes no conteúdo de um documento, tais como tags, estilos de fontes, metadados. O principal objetivo da eliminação de marcas é permitir a manipulação de arquivos de diferentes formatos. A existência de inúmeros formatos de documentos aliada à velocidade de surgimento de novas extensões e de atualizações de versão que não guardam compatibilidade com as versões anteriores são fatores complicadores para a atividade que depende, fundamentalmente, da definição de filtros apropriados para tratamento das diferentes codificações.

\subsection{Segmentação de Texto}

A segmentação de texto é a atividade que busca a divisão do texto em sentenças individuais [8]. Cada sentença identificada limita um conjunto semântico mínimo para definição de uma proposição. A segmentação de textos é realizada por meio da identificação de caracteres finalizadores de sentenças, principalmente, dos sinais de pontuação. A dificuldade desta atividade está na correta associação dos sinais de pontuação ao fim de sentença, uma vez que tais sinais também podem demarcar abreviações de nomes, separação de dígitos em datas, horas, números de telefones e números ordinais [9].

\subsection{Tokenização}

A terceira atividade é a atividade de identificação de tokens, ou seja, de elementos de cada oração, inclusos neste conjunto: palavras, números e sinais de pontuação. Essa etapa utiliza-se, basicamente, de sinais gráficos, como espaços, e algoritmos para o reconhecimento de entidades limítrofes de um token. Segundo Cimiano [9], o uso dos espaços (em branco) nem sempre define de forma adequada as fronteiras das palavras, sobretudo de palavras compostas e de nomes próprios. Por isso, é recomendada a utilização conjunta tokenizador e técnicas de reconhecimento de nomes de entidades.

\subsection{Análise Lexical}

A atividade "Análise Lexical" consiste em determinar, para cada token a etiqueta morfológica correspondente. A etiqueta morfológica, também conhecida como classe de palavras, identifica substantivos, verbos, pronomes, preposições, advérbios, conjunções, artigos etc.

A saída desta atividade é um arquivo contendo tokens anotados por suas respectivas etiquetas morfológicas. A dificuldade da atividade está na desambiguação semântica do token, pois uma mesma palavra pode ser classificada em diferentes classes gramaticais, de acordo com o contexto de seu uso.

\subsection{Reconhecimento de Elementos Centrais}

A quinta atividade, "Reconhecimento de Elementos Centrais", tem por objetivo produzir um conjunto de elementos que serão candidatos a conceitos e relações de mapas conceituais. Para isso, recebe-se como entrada o conjunto de tokens etiquetados morfologicamente e realiza-se um processamento utilizando técnicas de chunking.

O chunking - também conhecido como uma análise sintática parcial ou superficial - aplica técnicas de processamento superficial, tipicamente caracterizados por autômatos finitos e expressões regulares, para manter o agrupamento de palavras, formando constituintes com significados, tipicamente com um núcleo que é modificado por outras palavras da unidade [9]. Em português, as principais sequências de palavras ordenam-se em torno de um nome (Sintagma Nominal), verbo (Sintagma Verbal) ou são precedidas por preposições (Sintagma Preposicional). Esses arranjos são denominados genericamente de "chunks linguísticos".

A construção de mapas conceituais requer, ainda, a distinção de conceitos e de palavras de ligação (relações), pois ambos são importantes como unidades de linguagem, mas executam papéis diferentes na transmissão do significado. Enquanto conceitos são rotulados por palavras que representam coisas e eventos, as relações são uma forma de ligar dois conceitos em uma forma proposicional. Não há nenhuma correlação direta entre elementos de mapas conceituais e chunks linguísticos, todavia, de acordo com as orientações de construção de um mapa conceitual, podemos considerar que Sintagmas Nominais 
(SN), Sintagmas Verbais (SV) e Sintagmas Preposicionais (SP) são candidatos primários ao mapeamento dos elementos centrais de mapas conceituais. O Sintagma Nominal (SN) é o principal candidato ao conceito, o Sintagma Verbal (SV), por sua vez, é um aspirante a se tornar uma relação e o Sintagma Preposicional (SP) pode ser tanto um conceito já associado com a relação, tomando como essência o Sintagma Nominal precedido de preposição, ou uma relação, caso consideremos verbos ou locuções verbais precedidos de preposição. Os chunks identificados são, portanto, mapeados para elementos candidatos a conceitos e relações. O mapeamento de um chunk para um conceito ou uma relação dependerá, primordialmente, da possibilidade de estabelecer conexões entre estes elementos na forma de proposições.

\subsection{Interpretação de Dependências}

Tomando cada um dos candidatos a elementos de mapas conceituais, o interpretador de dependências transforma o candidato a elemento de mapa conceitual em um grafo. Um grafo é uma estrutura matemática de representação de dados, definida como um par ordenado $\mathrm{G}=$ $(\mathrm{V}, \mathrm{E})$, formado por um conjunto $\mathrm{V}$ de vértices e um conjunto $\mathrm{E}$ de arestas, que representam relações entre os vértices.

Os candidatos a elementos de mapas conceituais identificados pelo interpretador de dependências podem ser arestas ou elementos híbridos compostos simultaneamente de um vértice e uma aresta.

$\mathrm{Na}$ atividade, verifica-se o tipo do chunk: aqueles com núcleos verbais ou preposicionais são mapeados em arestas e os chunks com núcleos nominais são mapeados em vértices. À medida que os elementos são transformados em vértices ou arestas, o interpretador busca a posição mais adequada no grafo para subsumir o novo elemento; a subsunção ocorre por meio da identificação da proximidade dos elementos candidatos, unindo aqueles que possuem maior afinidade, de acordo com regras de aproximação pré-definidas.

\subsection{Construção de Mapas Conceituais}

A última atividade do processo é aquela que consiste na definição de proposições, baseadas em um grafo de entrada, denominada de "Construção de Mapas Conceituais". O grafo determina caminhos pelos quais se pode formar proposições, pois a cada caminho que parte de um conceito, passando por uma relação que leva a outro conceito, uma proposição é identificada. Ao fim da atividade, chega-se a um conjunto de proposições, determinando-se à representação do conteúdo textual por meio de conexões entre conceitos em um mapa conceitual.

\section{Estudo de Caso}

Para a validação do processo proposto para a construção de mapas conceituais a partir de textos, a pesquisa realizou um estudo de caso baseado em duas etapas: (i) implementação de um protótipo computacional e (ii) condução de testes por meio do protótipo.

\subsection{Protótipo Computacional}

Com o intuito de validar a abordagem proposta, desenvolvemos um protótipo computacional denominado de Text2Cmap. O protótipo foi implementado utilizando a linguagem de programação Python 2.6.5 [10].

A versão $\alpha$ do Text2Cmap é composta por cinco módulos que realizam as atividades do modelo de processo proposto, por meio do mapeamento detalhado na Figura 3.

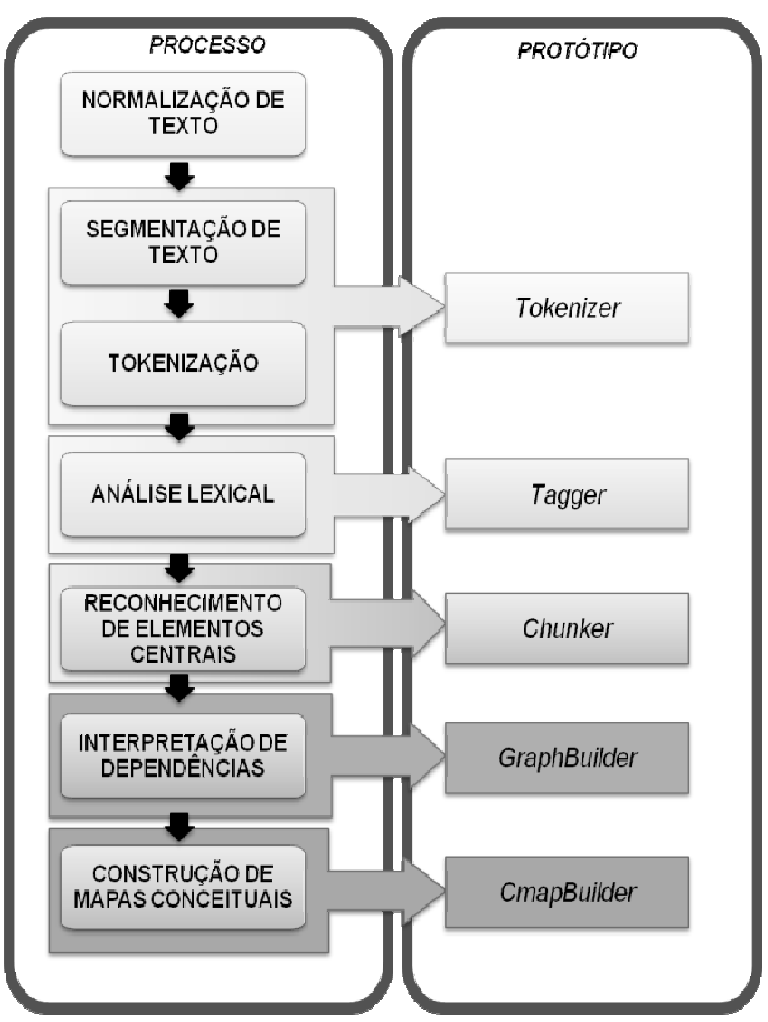

Figura 3. Modelo de Processo para Construção de Mapas Conceituais a partir de Textos

O módulo Tokenizer realiza as atividades de leitura do documento, segmentação do texto em sentenças e a tokenização, todas por meio de recursos do módulo de processamento de linguagem natural chamado de Natural Language Processing Toolkit (NLTK) [8].

O módulo Tagger realiza a atividade conhecida como "POS Tagging”, ou etiquetagem morfológica. Para esta atividade, optamos pelo uso do software livre Freeling, 
[11] com as configurações para a Língua Portuguesa de Garcia e Gamallo [12]. Após execução, o módulo Tagger produz como saída o conjunto de tokens seguidos por suas respectivas etiquetas morfológicas, lemas ${ }^{1}$ e probabilidades. Desta saída, geramos outra, mais simplificada, contendo apenas os tokens e as etiquetas.

O módulo Chunker reconhece grupos de tokens a partir de um conjunto de expressões regulares descritas por meio de cadeias de etiquetas morfológicas. Por meio do processo de chunking são identificados os candidatos a elementos de mapas conceituais. A princípio, o protótipo foi desenvolvido para reconhecer 16 tipos de elementos.

O módulo GraphBuilder executa a atividade de construção do grafo que intermedeia a construção do mapa conceitual. Para isso, o módulo toma cada um dos elementos reconhecidos pelo chunker, denominados de "candidatos" e os transforma em vértices de grafos, os quais são classificados como "conceitos", "híbridos" ou "link". O elemento do tipo "conceito" é um candidato a conceito de mapas conceituais, o elemento "link", um candidato a uma relação e o "híbrido", um misto entre conceitos e relações. A composição do grafo é realizada por meio de um algoritmo de busca baseado em uma função heurística, no qual caminha-se pelo grafo, a partir de um vértice até encontrar um vértice candidato a ser o subsunçor. A escolha do vértice leva em consideração o peso e a distância do vértice a ser subsumido em relação ao vértice pai. Quanto menor a distância, maior a probabilidade de existência de relacionamento entre os dois elementos. A geração de arquivos de grafos compatíveis com Graphviz [13], no formato "dot”, é feita por meio do módulo GvGen [14] e a visualização é feita pela ferramenta "GVEdit" do próprio pacote Graphviz.

O módulo CmapBuilder realiza a atividade fim do protótipo, ou seja, caminha pelo grafo, buscando a extração de proposições. A proposição é formada sempre que for possível caminhar de um elemento do tipo "conceito" a um elemento do tipo "híbrido", ou de um elemento "conceito", passando por um tipo "link" e chegando e um elemento "conceito". No fim do processo, há um conjunto de proposições formadas cuja organização gráfica leva ao mapa conceitual. No protótipo, não há módulo de visualização, por isso, lançamos mão da ferramenta CmapTools [15].

\subsection{Exemplo de Processamento}

Apresentamos algumas saídas decorrentes da execução do Text2Cmap. O processamento de um documento qualquer leva à produção sequenciada de um conjunto de saídas que permitem o acompanhamento e a rastreabilidade das ações realizadas.
É por meio destas saídas que o processo subjacente ao protótipo permite o acompanhamento e a rastreabilidade das ações realizadas.

Nas Figuras de 4 a 7 estão ilustrados trechos e algumas das saídas produzidas do processo.

Pode-se observar, na Figura 4, a saída do módulo Tagger em que uma sentença submetida ao Tagger originou uma sentença anotada por meio de etiquetas morfológicas. Por exemplo, o léxico "governador" é etiquetado por "NCMS000", que equivale dizer que se trata de um "Nome Comum no Masculino e no Singular". Por sua vez, "Mário_Pereira" é anotado com "NP00000" que significa "Nome Próprio".

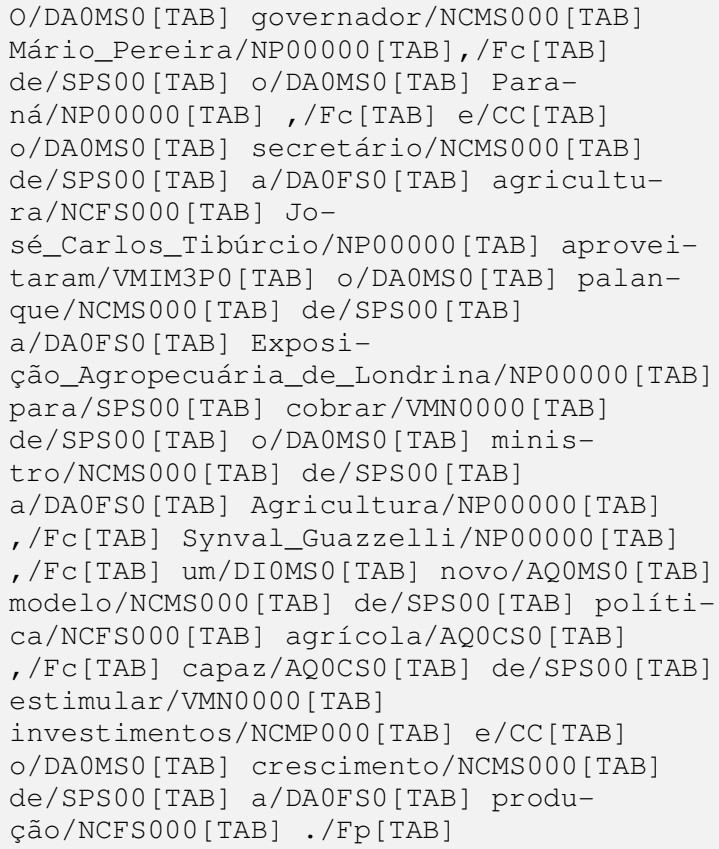

Figura 4. Saída do Tagger

A Figura 5 exibe o conteúdo de um arquivo originado pelo módulo Chunker, a implementação da atividade de "Reconhecimento dos Elementos Centrais". É possível observar que os léxicos agora encontram-se agrupados. Considere o trecho "(NP O/DA0MS0 (NP governador/NCMS000 Mário_Pereira/NP00000))". Nesse exemplo, o conjunto de léxicos \{“O”, "governador”, "Mário_Pereira" $\}$ foi agrupado como um único elemento classificado como um Sintagma Nominal. São esses elementos que serão transformados em vértices e arestas de um grafo.

\footnotetext{
${ }^{1}$ Em linguística, lema é a forma canônica de uma palavra.
} 


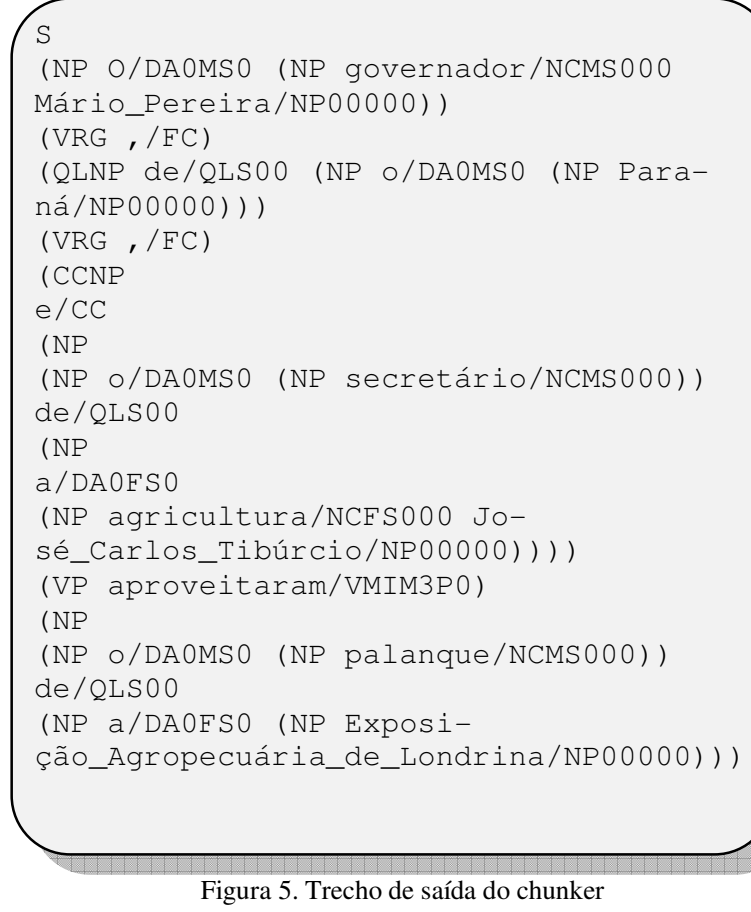

Figura 5. Trecho de saída do chunker

A Figura 6 apresenta os elementos identificados pela atividade anterior posicionados na forma de um grafo.

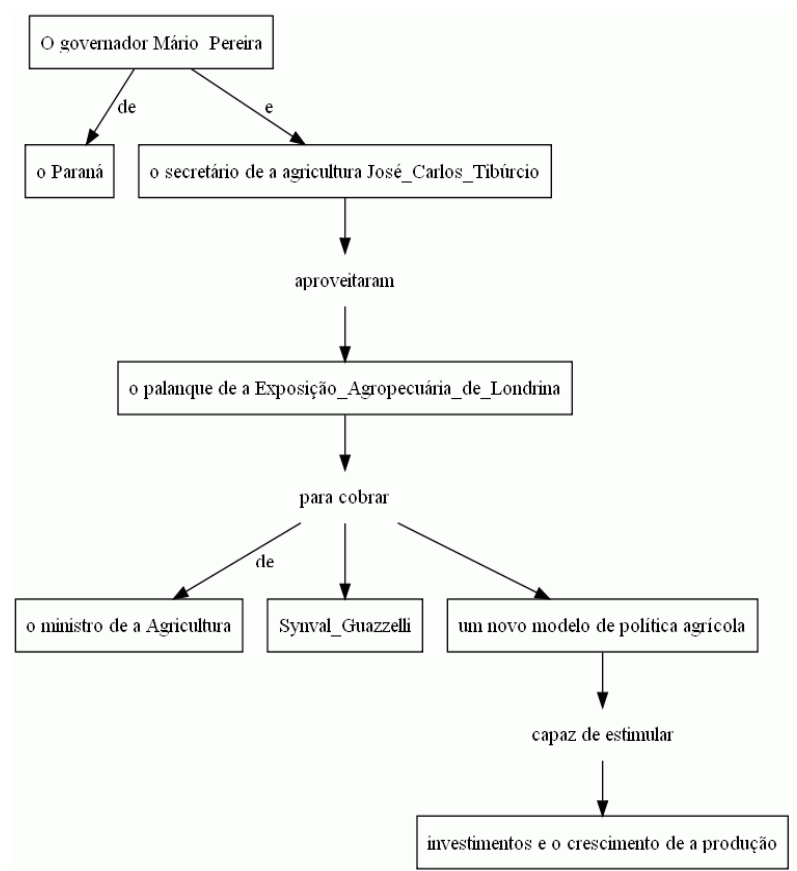

Figura 6. Trecho de saída do GraphBuilder

Finalmente, na Figura 7, o mapa conceitual é construído a partir das proposições geradas pelo CmapBuilder.

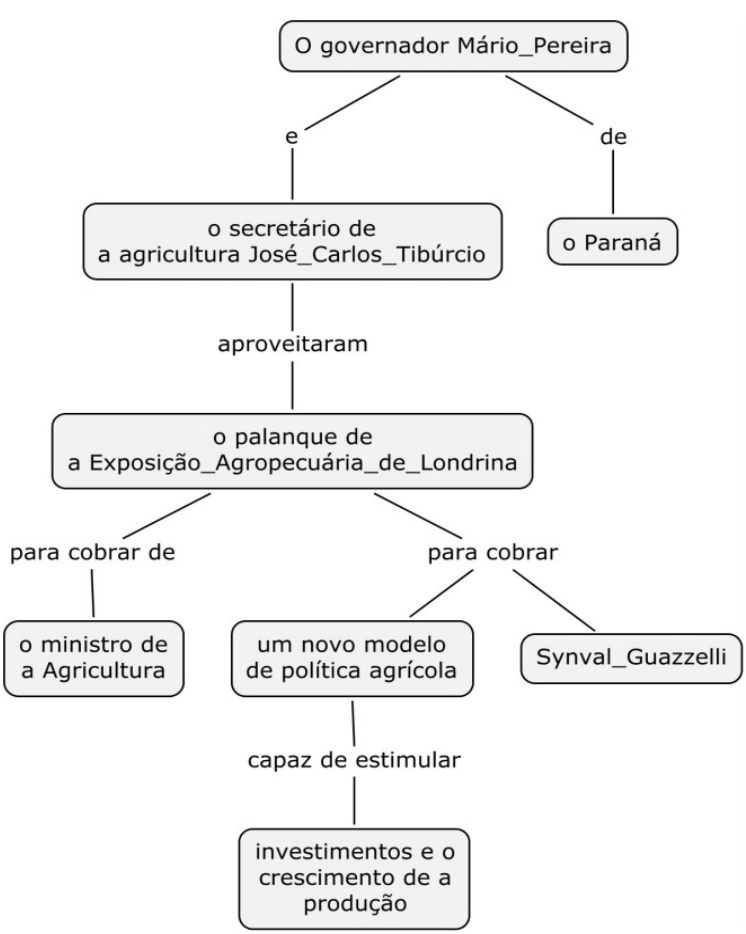

Figura 7. Trecho de saída do CmapBuilder

\subsection{Avaliação com Corpus Linguístico}

O Mac-Morpho é um corpus fechado e anotado, em português do Brasil, desenvolvido no contexto do projeto Lácio-Web [17]. Mac-Morpho contém aproximadamente 1,2 milhões de palavras que foram etiquetadas pelo parser Palavras e, posteriormente, cada etiqueta foi mapeada para o elemento correspondente no conjunto de etiquetas do Projeto Lácio-Web. A anotação morfossintática foi validada manualmente. O corpus é composto por 109 arquivos em texto puro, que por sua vez traduzem-se em 51.397 sentenças. Do corpus Mac-Morpho, utilizamos uma amostra, denominada de A1, que contém aproximadamente $2 \%$ do volume total dos textos, selecionados de forma aleatória.

\subsection{Resultados do Experimento}

Considerando exclusivamente o resultado quantitativo do processamento da amostra A1, é possível definir quatro grupos, distintos, conforme ilustrado na Tabela 1:

- G1: Documentos que levaram à formação de mapas com aumento da quantidade de tokens;

- G2: Documentos que levaram à formação de mapas conceituais com redução parcial da quantidade de tokens;

- G3: Documentos que levaram à formação de mapas conceituais sem redução da quantidade de tokens; e 
- G4: Documentos que não levaram à formação de mapas conceituais, ocasionado pela redução total do quantitativo de tokens.

\subsection{Análise dos Resultados Obtidos}

A seguir, analisamos a abordagem proposta, considerando os dados coletados a partir do processamento da amostra $A 1$ pelo protótipo Text2Cmap.

Ao final do processamento, é natural que nos perguntemos sobre a efetividade da abordagem na construção de mapas conceituais de qualidade. Nesta pesquisa, entendemos como qualidade os aspectos que fazem com que o mapa conceitual seja, além de legível, propício ao entendimento humano.

A avaliação da legibilidade e da compreensibilidade de um mapa conceitual sob a perspectiva humana requer igualmente uma análise estritamente humana. A questão imposta consiste na sujeição desta natureza de análise às interpretações de ordem subjetiva, pois a compreensão não se dá de forma uniforme em um grupo de pessoas: o que é de fácil entendimento para uns pode não o ser para outros. Se por um lado, tratar a subjetividade da análise é um desafio, por outro, a condução de um estudo sobre aspectos associados à compreensibilidade sem a interferência humana requer o desenvolvimento de mecanismos de interpretação semântica que extrapolam, sobremaneira, o escopo desta pesquisa.

Dado os fatos, certos de que o viés quantitativo é preferível àquele suscetível ao discernimento e opinião de cada indivíduo que realiza a análise, optamos por uma redução do conceito de compreensibilidade e legibilidade do mapa, associando-o ao conceito de "fidelidade semântica".

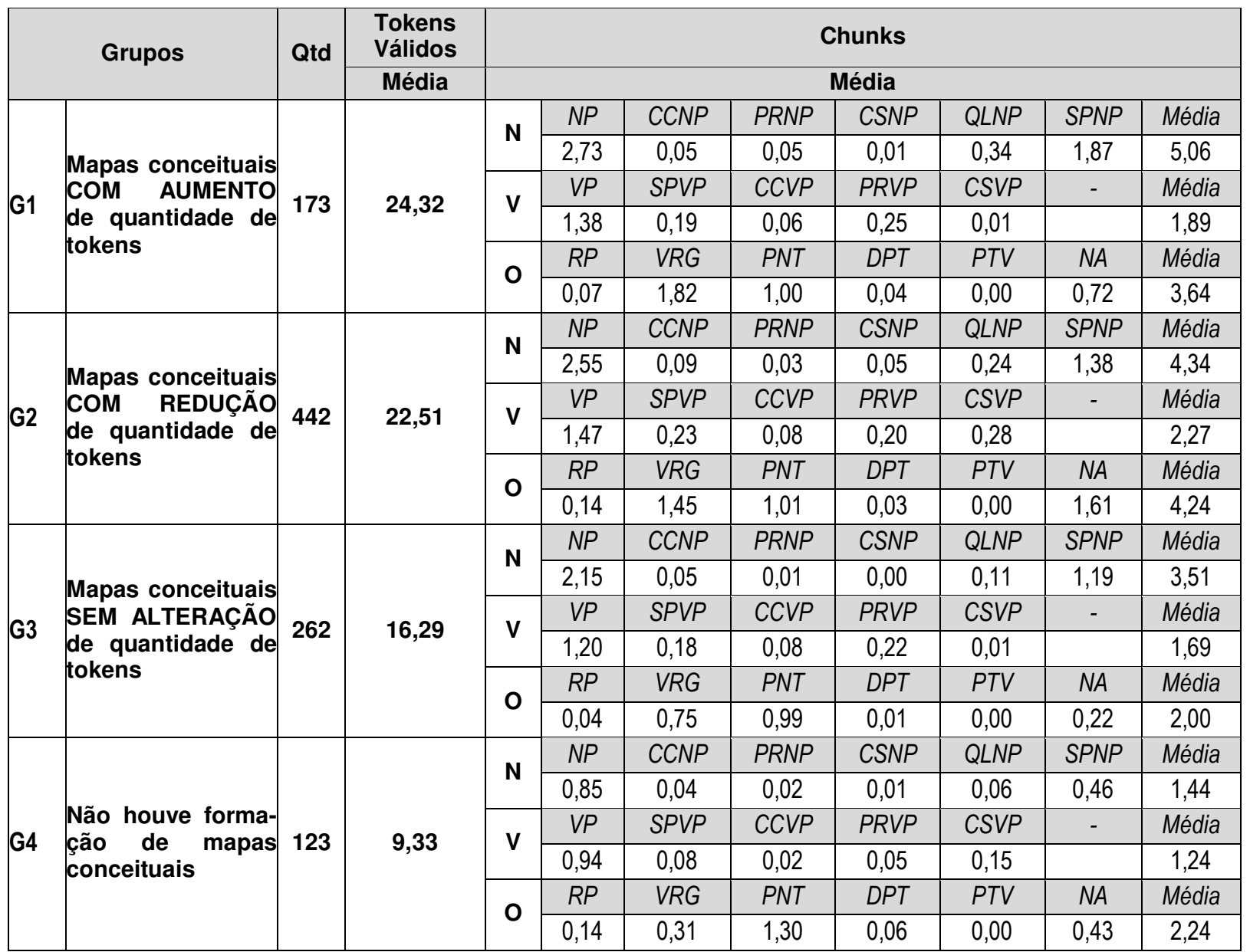

Tabela 1. Formação de Clusters de Acordo com a quantidade de tokens do documento original e do mapa conceitual construído

Sendo o documento original portador de aspectos que lhe garantam o entendimento humano, partimos da premissa de que a fidelidade do mapa conceitual construído ao conteúdo manipulado manterá tais características, se forem conservados os seus elementos originais. 
Como indicador do grau de fidelidade com a fonte de dados original, definimos o nível de perda de tokens ao longo do processo. Embora a perda de tokens não seja um indicador direto de perda semântica ou de compreensibilidade, podemos, indiretamente, associar a perda de tokens no processo de construção à existência de lacunas semânticas que prejudicariam a compreensão do conteúdo do mapa conceitual.

Desta forma, entendemos que na base do indicador de fidelidade estão estrutura de componentes do documento original comparado aos componentes exibidos pelo mapa conceitual, excluindo-se da contagem os tokens referentes aos sinais de pontuação.

Observou-se que documentos com poucos chunks verbais e nominais dificultam a criação de proposições, como vistos no grupo G4, que apresenta uma baixa densidade desses elementos e perda total de tokens no processo. Neste grupo, com média de tokens reduzidos em comparação aos demais grupos, os chunks nominais ocorrem em média, 1,44 para 1,24 verbais. Como a relação mínima para a formação de proposições é de dois conceitos para uma relação, é requerido ao menos dois chunks nominais para um verbal.

Nos grupos G1, G2 e G3 houve a formação de mapas conceituais. Notadamente, o grupo G1 foi o que mais

\begin{tabular}{|c|c|c|c|}
\hline Natureza do Erro & Descrição & Documento & Saída do Processo \\
\hline Erro de tagger & $\begin{array}{l}\text { Termo "equipe" reconhecido } \\
\text { pelo tagger como verbo, ao } \\
\text { invés de substantivo }\end{array}$ & fc96ma23_0083 & $\begin{array}{l}\text { A/DA0FSO } \\
\text { equipe/VMSP1S0 }\end{array}$ \\
\hline Erros sintáticos & $\begin{array}{l}\text { Artigo definido finalizando a } \\
\text { sentença. }\end{array}$ & ag94ab12_0003 & $\begin{array}{l}\text { em/SPSO0 } \\
\circ / \mathrm{DAOMSO} \\
(\mathrm{PNT} . / \mathrm{FP}))\end{array}$ \\
\hline Erros de chunker & $\begin{array}{l}\text { Chunker incapaz de identificar } \\
\text { artigos que precedem sintag- } \\
\text { mas nominais }\end{array}$ & ag94ab12_0074 & 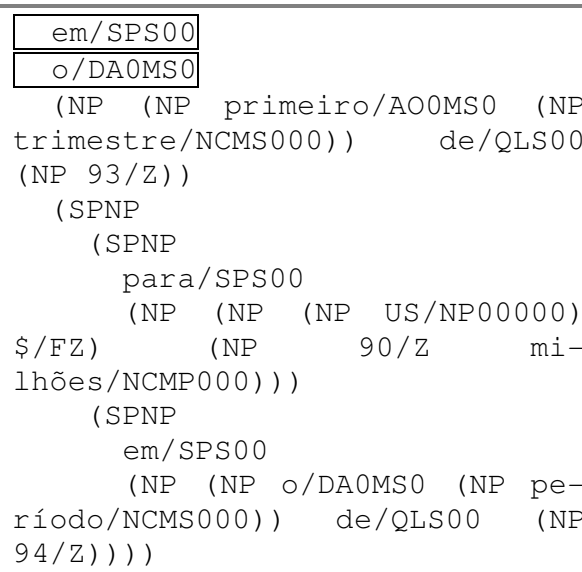 \\
\hline
\end{tabular}

Tabela 2. Exemplos de falhas no processo que ocasionam perda de tokens

As perdas no processamento, de origem nos erros sintáticos e de chunker, indicam a insuficiência da abordagem no tratamento de muitos fenômenos presentes em um texto escrito em linguagem natural. Nesse sentido, direcionam a pesquisa no sentido da busca pelo aperfei- produziu proposições em relação aos outros dois grupos: 3,89 comparados aos 2,88 do grupo G2 e aos 2,40 do grupo G3. Coincidentemente, o grupo G1 é o que apresenta a melhor relação entre chunks nominais e verbais: 5,01 para 1,88 .

A observação da Tabela 1, em que estão enumerados os chunks, é um indicativo para a identificação das causas para a perda de tokens durante o processo de construção de mapas conceituais.

Um dos casos que ilustram as causas de perdas de forma significativa está nos artigos definidos e indefinidos não reconhecidos em um documento. A gramática utilizada por esta pesquisa para o processo de chunking admite a presença do artigo definido e indefinido como parte de um sintagma nominal. Não sendo possível identificá-lo dessa forma, reconhecemos as falhas mais proeminentes do processo, algumas das quais estão ilustradas na Tabela 2.

As falhas de origem no tagger apontam a existência de erros de associação da etiqueta morfológica decorrente de ambiguidades das palavras. A escolha do etiquetador, portanto, passa a ser um elemento central do processo quando implementado computacionalmente. 
Mas, considerando a impossibilidade de tratar os fenômenos linguísticos à exaustão, caberia outra forma de endereçamento do problema, focado muito mais na busca por textos que apresentem estruturas adequadas para construção de mapas conceituais, do que, necessariamente, na possibilidade de tratamento de todas as estruturas possíveis na Língua Portuguesa.

Em nosso estudo de caso, notamos que os métodos e técnicas linguísticas combinadas aos algoritmos de busca permitiram a definição de uma solução viável para a construção de mapas conceituais a partir de textos em português do Brasil. Encontramos na abordagem linguística o esteio para a preservação de características semânticas dos conteúdos de documentos submetidos ao processo de construção dos mapas conceituais.

Mesmo em situações em que houve perda de elementos estruturais do texto, os métodos linguísticos atuaram no sentido de favorecer a identificação do prejuízo semântico e as possíveis causas das ocorrências.

Além do que citamos, some-se o fato de que o uso de recursos linguísticos está cada vez mais acessível ao pesquisador que já pode lançar mão de bibliotecas inteiras para manipulação de linguagem natural e de ferramentas específicas para análise lexical, sem a necessidade de preocupação com minúcias relacionadas com a implementação de teorias linguísticas.

\section{Considerações Finais e Trabalhos Futuros}

Queremos concluir, prestando contas sobre os resultados alcançados por esta pesquisa.

Iniciamos retomando as hipóteses levantadas na fase inicial de investigação, enumeradas no capítulo introdutório.

Confirmamos a hipótese que versava sobre a adequação dos métodos e técnicas de processamento de linguagem natural para o endereçamento do problema de construção de mapas conceituais a partir de textos.

Em pesquisa bibliográfica conduzida por esta pesquisa e relatada no Seção 3, observamos que de um total de 15 abordagens analisados, cinco das 10 abordagens que lidaram com fontes de dados não estruturadas produziram mapas conceituais ditos "completos" por meio de métodos híbridos e métodos linguísticos. Neste levantamento foi constatado que os métodos estatísticos não foram capazes de produzir mapas conceituais com conceitos e relações nomeadas.

Em nosso estudo de caso, notamos que os métodos e técnicas linguísticas combinadas aos algoritmos de busca permitiram a definição de uma solução viável para a construção de mapas conceituais a partir de textos em português do Brasil. Encontramos na abordagem linguística o esteio para a preservação de características semânticas dos conteúdos de documentos submetidos ao processo de construção dos mapas conceituais. Mesmo em situações em que houve perda de elementos estruturais do texto, os métodos linguísticos atuaram no sentido de favorecer a identificação do prejuízo semântico e as possíveis causas das ocorrências.

Observamos que é possível correlacionar elementos constituintes de textos e os elementos presentes no mapa conceitual.

Apesar de não ter sido encontrada na literatura declaração explícita sobre a correspondência de elementos textuais e os conceitos e relações de um mapa conceitual, em nossa abordagem, consideramos a possibilidade de uso de grupos linguísticos para avaliação da hipótese. Consideramos que os elementos constituintes de um texto devem ser identificados com vistas à formação de conceitos e relações. Para isso, foi necessário quebrar o texto em sentenças e em seguida, em elementos atômicos, denominados de tokens. O conjunto de tokens, essencialmente formado por palavras, números e sinais, foi encaminhado para um processo de análise lexical, visando posterior reagrupamento na forma de grupos reduzidos de palavras, chamados de chunks linguísticos.

Cada um dos chunks reconhecidos foi considerado um candidato em potencial a se tornar um elemento de mapa conceitual. Os chunks de núcleo nominal foram mapeados como candidatos a conceitos e os de núcleo verbal foram considerados como candidatos a relações. Embora o mapeamento entre os candidatos potenciais e os elementos de mapa conceitual não fosse direto, sendo necessária a definição de uma heurística, o grau de proximidade entre a definição de conceito e relações aos chunks nominais e verbais, respectivamente, permitiu a inferência de que há sim, um nível de correlação entre os elementos constituintes de textos e os elementos de mapas conceituais.

A identificação de chunks nominais e verbais remete à validação da hipótese de que seria possível adotar a gramática sintagmática para identificação de elementos constituintes. Com efeito, vimos ser possível estruturar os elementos do texto em forma de sintagmas de ordem nominal, verbal e proposicional que podem ser mapeados a elementos de mapas conceituais. Em nosso estudo de caso, entretanto, nos deparamos com situações em que foi necessário o uso de chunks que não necessariamente correspondem os tipos presentes na gramática sintagmática. Embora, grande parte do processo de construção seja realizada por meio dos sintagmas, há chunks que necessitam ser considerados na manutenção da semântica e que não representam, necessariamente, uma realização sin- 
tagmática. Portanto, a hipótese não foi confirmada por completo, apesar de responder por grande parcela do processo.

Comprovamos que o uso de grafos como estruturas de dados intermediárias entre textos e mapas conceituais é factível. A extensa literatura sobre métodos caminhamento em grafos, bem como a pesquisa consolidada na área, garantiu êxito na aplicação de grafos na intermediação entre o conteúdo do documento e o mapa conceitual. O grafo possibilita uma visão preliminar das dependências entre elementos que levam à formação de um mapa conceitual. E, pelo caminhamento pelo grafo, comprovamos a viabilidade de reconhecimento de proposições.

O objetivo principal da pesquisa se resume na definição de uma abordagem computacional que permita a construção de mapas conceituais a partir de textos em português do Brasil.

Sob o ponto de vista da definição da abordagem computacional, consideramos que a pesquisa foi bem sucedida, na medida em que especificou o processo e as atividades de construção, compartilhando o conhecimento que possibilitará a continuidade do trabalho por outros pesquisadores. Na ótica de viabilidade de uso da abordagem, a implementação de um protótipo computacional que realiza o processo foi determinante. Pelo protótipo computacional pudemos avaliar as forças e fraquezas da abordagem, bem como as oportunidades de melhoria.

De modo geral, provamos ser possível a construção de mapas conceituais a partir de textos em português do Brasil, assegurando indicadores objetivos e quantitativos para a apuração da perda semântica do processo, examinando os métodos e técnicas mais proeminentes nesta área de pesquisa, e definindo um mapeamento entre constituintes da língua portuguesa e os mapas conceituais.

Em relação à conformidade com os preceitos da Teoria da Aprendizagem, consideramos que a estrutura do conteúdo do texto deve comportar, de forma indireta, as premissas de organização do conhecimento, haja vista ser uma boa prática a introdução de conceitos básicos antes dos conceitos mais trabalhados.

Finalmente, acreditamos que a pesquisa apresentou uma abordagem para a construção de mapas conceituais que pode ser caracterizada pela definição de objetivos educacionais, o uso de fontes de dados não estruturadas e independentes de domínio, a aplicação de recursos híbridos para a manipulação da fonte de dados e a produção de mapas conceituais de forma semiautomática, avaliadas subjetivamente e que apresentam o formato de um grafo completo.

Pequenas alterações na abordagem poderiam melhorar de imediato alguns dos resultados aqui apresentados. A primeira delas seria o aperfeiçoamento do método utili- zado para realizar a segmentação das sentenças e dos tokens, definindo padrões linguísticos mais abrangentes que pudessem reconhecer cifras e locais com maior destreza.

Outro ponto de melhoria consiste na alteração da gramática para a identificação dos elementos candidatos a mapas conceituais. Observamos que vários advérbios foram descartados, bem como as conjunções e artigos, simplesmente porque não havia uma expressão regular que previsse a ocorrência destes em certas posições da oração.

Além destes, é necessário avaliar outros etiquetadores morfossintáticos. Nesta pesquisa, escolhemos o tagger Freeling de forma arbitrária, após tentativas com outros etiquetadores para a Língua Portuguesa. Portanto, pesquisa que comparasse a efetividade dos taggers para o português do Brasil, considerando o contexto da construção de mapas conceituais a partir de textos, seria uma contribuição relevante na continuidade desta pesquisa.

Trabalhos futuros devem considerar a possibilidade de aprofundamento nas questões linguísticas, sobretudo na definição de mecanismos mais robustos no tratamento de anáforas, número, gênero, sentenças interrogativas e imperativas, além de refinar heurísticas para definição dos grafos e identificação das proposições. Outro aspecto igualmente relevante seria a seleção de textos adequados para a extração de proposições. Para isso, sugere-se a realização de experimentos que permitam a avaliação dos resultados com textos de uma ou outra natureza.

Será também necessário definir no protótipo um módulo para atuar na normalização dos documentos, de forma a ampliar o leque das possibilidades de uso da ferramenta. Aliás, a ferramenta, construída de forma experimental para ser um protótipo carece de inúmeras evoluções para que se torne, de fato, uma ferramenta útil ao usuário final, leigo das questões tecnológicas. Uma vez que a ferramenta puder ser disponibilizada para o uso em sala de aula, caberia novo estudo de caso para averiguar a relevância dos mapas conceituais produzidos, desta vez, sob a perspectiva qualitativa.

\section{Referências}

[1] J. Delors, et al. Educação: Um Tesouro a Descobrir; Relatório para a UNESCO da Comissão Internacional sobre Educação para o século XXI. 281p., UNESCO, MEC, Cortez Editora, 1999.

http://www.dominiopublico.gov.br/download/te xto/ue000009.pdf, maio 2010.

[2] L. P. L. Mercado (Org). Formação docente e novas tecnologias. In: Novas tecnologias na educação: reflexões sobre a prática. 210 p., 
Maceió: EDUFAL, 2002.

[3] L. Dowbor. Tecnologias do conhecimento: os desafios da educação. Petrópolis: Vozes, 2001.

[4] E. T. da Silva. Revalorização do livro diante das novas mídias. Veículos e linguagens do mundo contemporâneo: a educação do leitor para as encruzilhadas da mídia. In: Integração das Tecnologias na Educação. Salto para o Futuro. M. E. B. de Almeida, J. M. Moran (Org). $204 \quad$ p. 2005. http://portal.mec.gov.br/seed/arquivos/pdf/1sf.p df, maio 2010

[5] A. J. Canãs et al. Summary of Literature Pertaining to the Use of Concept Mapping Techniques and Technologies for Education and Performance Support, 2003. http://www.ihmc.us/users/acanas/Publications/ ConceptMapLitReview/IHMC\%20Literature\% 20Review\%20on\%20Concept\%20Mapping.pdf, junho 2009.

[6] J. D. Novak, D. B. Gowin. Learning how to learn. Cambridge University Press, 1984.

[7] J. H. Kowata, D. Cury, M. C. S. Boeres. Caracterização das Abordagens para Construção de Mapas Conceituais. In Anais do XX Simpósio Brasileiro de Informática na Educação (SBIE), 2009.

[8] S. Bird, E. Klein, E. Loper. Natural Language Processing with Python - Analyzing Text with the Natural Language Toolkit, CA: O'Reilly Media, 2009.

[9] P. Cimiano. Ontology Learning and Population from Text: Algorithms, Evaluation and Applications, Springer Science, 2006.

[10] Python 2.6.5. Python Programming Language Official Website, 2010. http://www.python.org/download/releases/2.6.5 I, março 2010.

[11] J. Atserias et al. "FreeLing 1.3: Syntactic and semantic services in an open-source NLP library". In Proceedings of the fifth international conference on Language Resources and Evaluation (LREC 2006), ELRA. Italy, 2006. http://www.lsi.upc.edu/ nlp/freeling.

[12] M. Garcia, P. Gamallo. Using Morphosyntactic Post-processing to Improve POS-tagging Accuracy. In: Proceedings of the International Conference on Computational Processing of the Portuguese Language (PROPOR'2010). Porto
Alegre, RS, 2010.

[13] Graphviz 2.26.3. Graphviz Project Website, 2010.

http://www.graphviz.org/Download_windows.p hp., março 2010.

[14] GvGen 0.9. GvGen Project Website, 2007. http://software.inl.fr/trac/wiki/GvGen, março 2010.

[15] J. D. Novak, A. J. Cañas. The Origins of the Concept Mapping Tool and the Continuing Evolution of the Tool. Information Visualization Journal, 5 (3), 2006, páginas 175-184.

[16] Maria Araceli. Ruiz-Primo; Richard. J. Shavelson. Problems and issues in the use of Concept Maps in science assessment. Journal of Research in Science Teaching, 33(6), 569 600, 1996.

[17] Frank. Safayeni; Natalia. Derbentseva; Alberto J. Cañas. Concept Maps: A Theoretical Note on Concepts and the Need for Cyclic Concept Maps, 2003. http://cmap.ihmc.us/publications/ResearchPaper s/Cyclic\%20Concept\%20Maps.pdf, abril. 2010.

[18] Alves, A. O., Pereira, F. C., \& Cardoso, A. (2001). Automatic Reading and Learning from Text. In: Proceedings of the International Symposium on Artificial Intelligence (ISAI'2001), (pp. 302-310). Fort Panhala (Kolhapur), India.

[19] Clariana, R. B., \& Koul, R. (2004). A Computer-Based Approach for Translating Text into Concept Map-Like Representations. In: A. J. Cañas, J. D. Novak, \& F. M. González (Ed.), In: Proceedings First International Conference on Concept Mapping (CMC'04), Volume 1, pp. 125-133. Pamplona, Spain.

[20] Graudina, V., \& Grundspenkis, J. (2008). Concept Map Generation from OWL Ontologies. In: A. J. Cañas, P. Reiska, M. Åhlberg, \& J. D. Novak (Ed.), In: Proceedings of the Third International Conference on Concept Mapping (CMC'08). Tallin, Estonia \& Helsinki, Finland.

[21] Lau, R. Y., Chung, A. Y., Song, D., \& Huang, Q. (2008). Towards Fuzzy Domain Ontology Based Concept Map Generation for E-Learning. In: Advances in Web Based Learning (ICWL 2007). 4823, pp. 90-101. Springer Berlin/Heidelberg.

[22] Richardson, R., \& Fox, E. A. (2007). Using Concept Maps in NDLTD as a Cross-Language. 
In: 10th International Symposium on Electronic Theses and Dissertations (ETD 2007). Uppsala, Sweden.

[23] Richardson, W. R., Srinivasan, V., \& Fox, E. A. (2008). Knowledge discovery in digital libraries of electronic theses and dissertations: an NDLTD case study. In: International Journal on Digital Libraries , 9 (2), 163-171.

[24] Bai, S.-M., \& Chen, S.-M. (2008). Automatically constructing concept maps based on fuzzy rules for adapting learning systems. In: Expert Systems with Applications , 35 (1), 41-49.

[25] Chang, T.-H., Tam, H.-P., Lee, C.-H., \& Sung, Y.-T. (2008). Automatic Concept Map Constructing using top-specific training corpus. In:Proceedings of the Asia-Pacific Educational Research Association Board Meeting (APERA'2008). Singapore.

[26] Chen, N.-S., Kinshuk, Wei, C.-W., \& Chen, H.J. (2008). Mining e-Learning domain concept map from academic articles. In: Computers \& Education, 50 (3), 1009-1021.

[27] Lee, C.-H., Lee, G.-G., \& Leu, Y. (2009). Application of automatically constructed concept map of learning to conceptual diagnosis of elearning. In: Expert Systems with Applications , 36 (2), 1675-1684.

[28] Tseng, S.-S., Sue, P.-C., Su, J.-M., Weng, J.-F., \& Tsai, W.-N. (2007). A new approach for constructing the concept map. In: Computers \& Education , 49 (3), 691-707.

[29] Gaines, B. R., \& Shaw, M. L. (1994). Using Knowledge Acquisition and Representation Tools to Support Scientific Communities. In: Proceedings of the twelfth national conference on Artificial intelligence (AAAI'94) , 1, 707714 .

[30] Kumazawa, T., Saito, O., Kozaki, K., Matsui, T., \& Mizoguchi, R. (2009). Toward knowledge structuring of sustainability science based on ontology engineering. In: Sustainability Science , 99-116.

[31] Pérez, C. C., \& Vieira, R. (2004). Aquisição de Conhecimento a partir de Textos para Construção de Mapas Conceituais. In: II Workshop de Teses e Dissertações em Inteligência Artificial (WTDIA 2004). São Luís, MA

[32] Pérez, C. C., \& Vieira, R. (2005). Mapas Conceituais: geração e avaliação. In: Anais do
III Workshop em Tecnologia da Informação e da Linguagem Humana (TIL'2005), (pp. 21582167). São Leopoldo, RS.

[33] Valerio, A., \& Leake, D. (2006). Jump-Starting Concept Map Construction with Knowledge Extracted from Documents. In: A. J. Cañas, J. D. Novak, \& F. M. González (Ed.), In: Proceedings Second International Conference on Concept Mapping (CMC'06), 1, pp. 296-303. San José, Costa Rica.

[34] Zouaq, A., \& Nkambou, R. (2008). Building Domain Ontologies from Text for Educational Purposes. In: IEEE Transactions on Learning Technologies, Volume 1 (1), p. 49-62.

[35] Zouaq, A., \& Nkambou, R. (2009). Evaluating the Generation of Domain Ontologies in the Knowledge Puzzle Project. In: IEEE Transactions on Knowledge and Data Engineering (10.1109/TKDE.2009.25).

[36] Manzano-Macho, D., \& Gómez-Pérez, A. (2005). An overview of methods and tools for ontology learning from texts. In: The Knowledge Engineering Review , 19 (3), 187212.

[37] Clariana, R. B., \& Koul, R. (2004). A Computer-Based Approach for Translating Text into Concept Map-Like Representations. In: A. J. Cañas, J. D. Novak, \& F. M. González (Ed.), In: Proceedings First International Conference on Concept Mapping (CMC'04), Volume 1, pp. 125-133. Pamplona, Spain.

[38] Diestel, R. (2005). Graph Theory (Eletronic Edition ed.). New York, USA: Springer Verlag / Heidelberg. 